\title{
Tradução: A Mente, a Medicina e o Homem, por Gregory Zilboorg
}

\section{Translation: Mind, Medicine \& Man, by Gregory Zilboorg}

Traducción: La Mente, la Medicina y el Hombre, por Gregory Zilboorg

Lorene Almeida Tiburtino-Silva ${ }^{1}$ João Alberto Mendonça Silva² Josemar de Campos Maciel ${ }^{3}$

${ }^{1}$ Doutoranda e mestre em Desenvolvimento Local pela Universidade Católica Dom Bosco. Graduada em Biologia. Desenvolve pesquisa sobre Ecodesign e Logística Reversa na perspectiva do Desenvolvimento Local e da Sustentabilidade. E-mail: Iorenetiburtino@yahoo.com.br, Orcid: http://orcid.org/0000-0003-0463-7132

${ }^{2}$ Doutorando e mestre em Desenvolvimento Local, e graduado em Filosofia pela Universidade Católica Dom Bosco (UCDB). E-mail: giambattista@gmail.com, Orcid: http://orcid.org/0000-0003-3167-9469

${ }^{3}$ Doutor em Psicologia pela Pontifícia Universidade Católica de Campinas. Mestre em Psicologia pela Universidade Católica Dom Bosco, e em Teologia Sistemática, pela Pontifícia Universidade Gregoriana de Roma. Graduado em Filosofia pelas Faculdades Unidas Católicas de Mato Grosso, e em Teologia, pela Pontifícia Universidade Gregoriana de Roma. Professor na Universidade Católica Dom Bosco no Mestrado em Desenvolvimento Local,

Programa Master em Desenvolvimento Territorial Sustentável (Master STEDE) Erasmus Mundus/Erasmus Plus e na Licenciatura em Filosofia. E-mail: maciel50334@yahoo.com.br, Orcid: http://orcid.org/0000-0001-8277-9422 
Resumo: O psicanalista e historiador da Psiquiatria Dr. Gregory Zilboorg, nascido russo e naturalizado americano, trabalhou por anos os aspectos da Psiquiatria dentro de um contexto sociológico e humanístico. Durante sua carreira, escreveu diversas obras de brilhante ilustração de conceitos para leigos. Seus livros são raros, mesmo em buscas virtuais, sendo poucas e privilegiadas as bibliotecas que possuem exemplares. Além deles, Zilboorg também produziu uma série de artigos clínicos, que discutem desde a personalidade esquizoide até as relações entre o Direito e a Psiquiatria. Aqui traduzimos parte de um capítulo de seu livro Mind, Medicine \& Man. Nesse trecho, Zilboorg ilustra a ideia de psiquismo humano a partir de uma brilhante descrição da ameba que, como ser vivo e unicelular e que percebe o mundo a partir de sua única célula, desenvolvendo um estilo próprio de comunicação com o ambiente. Zilboorg defende que o fenômeno psíquico envolve toda a corporeidade humana, analogamente ao ser vivo multicelular, para que o conjunto de informações se traduza nos diversos sistemas psíquicos.

Palavras-chave: Psicologia; biomimetismo; corporeidade.

Abstract: The psychoanalyst and historian of psychiatry Dr. Gregory Zilboorg, born Russian and naturalized American, has worked for years on aspects of psychiatry within a sociological and humanistic framework. During his career, he wrote several works of brilliant illustration of concepts for lay people. His books are rare to find nowadays, even in virtual searches. Only few and privileged libraries have copies of them. He has also produced a series of clinical articles, ranging from the schizoid personality to the relationship between Law and Psychiatry. Here we present a translation of some pages of his book Mind, Medicine \& Man. In this passage, Zilboorg illustrates the idea of human psyche departing from a brilliant description of the amoeba, which, as a single-celled living being, perceiving the world from its single cell, develops a unique style of communication with the environment. Zilboorg argues that the psychic phenomenon involves the totality of human corporeality, analogously to the multicellular living being, so that the information set is translated in the multifarious human psychic subsystems.

Keywords: Psycology; biomimetism; corporeity.

Resumen: El psicoanalista e historiador de la psiquiatría Dr. Gregory Zilboorg, nacido en Rusia y naturalizado estadounidense, trabajó durante años en los aspectos de la psiquiatría en un contexto sociológico y humanista. Durante su carrera, escribió varios trabajos brillantes de ilustración para laicos. Sus libros son raros, incluso en búsquedas virtuales, siendo pocas y privilegiadas las bibliotecas que tienen copias. Además de ellos, Zilboorg también ha producido una serie de artículos clínicos que discuten de todo, desde la personalidad esquizoide hasta la relación entre el derecho y la psiquiatría. Aquí traducimos parte de un capítulo de su libro Mind, Medicine \& Man. En este extracto, Zilboorg ilustra la idea de la psique humana a partir de una descripción brillante de la ameba que, como un ser vivo unicelular, percibe el mundo desde su única célula y aún desarrolla su propio estilo de comunicación con el entorno. Zilboorg argumenta que el fenómeno psíquico involucra toda la corporeidad humana, analoga al ser vivo multicelular, de modo que el conjunto de información puede traducirse a los diversos subsistemas psíquicos.

Palabras clave: Psicología; biomimética; corporeidad. 


\section{INTRODUÇÃO}

Muito tempo depois de o Dr. Gregory Zilboorg escrever o seu texto inspirado na forma como as amebas se relacionam com o meio ambiente e sobre como esse ensinamento pode trazer luz para os estudos de Neurologia Comportamental e Psiquiatria, ainda estamos buscando formas de aprender com a natureza.

Inúmeros exemplos poderiam ser descritos de pesquisadores que usaram de seus conhecimentos oriundos da observação da natureza, buscando entender um determinado fenômeno, mas aqui deixamos a lembrança de alguns.

Charles Darwin, com suas observações dos ecossistemas a bordo do HMS Beagle, propiciou todo um campo de conhecimento, do qual ele é chamado de patrono. Sua formação e suas reflexões sobre os processos que favorecem a especiação são intrinsicamente ligadas e, por isso, até hoje, mesmo com tantos esclarecimentos tecnológicos, recomenda-se a todos os estudantes a leitura de seu livro A origem das espécies.

Jean Piaget, considerado um dos maiores pensadores sobre a teoria do conhecimento, biólogo e psicólogo de formação, possibilitou o registro e a observação de novas hipóteses da cognição humana a partir do convívio diário com seus filhos pequenos.

A observação da natureza nos ensina diariamente a viver dentro de nossos meios e em harmonia com ela. Benyus (2008) cita que ainda existe certa relutância por parte dos pesquisadores em se voltar para os ensinamentos da natureza, o que não é o caso do texto que segue. No livro Biomimicry: innovation inspired, a autora cita o biomimetismo como uma forma de ter na natureza um modelo, uma medida e uma mentora.

Como é possível um sistema produzir e usar somente a energia que precisa? A melhor resposta encontra-se em modelos prontos na natureza; fotossíntese. Em outros exemplos, percebemos extensos estudos sobre a composição molecular das teias de aranha ou da aderência das patas das lagartixas.

Além dos ensinamentos da natureza, outra importante contribuição de Zilboorg é a análise holística, também conhecida como pensamento 
sistêmico, tão explorado por Capra (2005; 2006; 2010); sendo assim, a abrangência das propriedades de um sistema perpassa e surge das relações entre suas partes e da compreensão de um sistema dentro do contexto e de um todo maior.

Gregory Zilboorg (1890-1959) obteve dois diplomas no curso de Medicina, um em São Petersburgo, Rússia, e outro em Columbia, EUA. A partir de 1931, lecionou e praticou Psicanálise e Psiquiatria; entre seus livros, estão a História da Psicologia Médica (1941), Freud e Religião (1958) e Mente, Medicina e Homem (1943) - deste último, convidamos o leitor a apreciar o capítulo On Certain Misconceptions, Alguns Mal-Entendidos, com o intuito de estimular o pensamento biomimético e holístico e, evidentemente, a prática de um experimento mental.

\section{ALGUNS MAL-ENTENDIDOS}

O texto que segue é a tradução do capítulo On Certain Misconceptions (Alguns Mal-Entendidos), do livro Mind, Medicine and Man (Mente, Medicina e Homem), de 1943, escrito por Gregory Zilboorg.

Há minúsculos organismos vivos que são compostos por apenas uma célula. Estes organismos unicelulares poderiam ser chamados de coisas vivas em vez de organismos, porque eles não têm órgãos diferenciados eles são exatamente minúsculas bolhas vivas de protoplasma, como uma única célula cerebral ou uma única célula de fígado, pulmão ou estômago. Há esta diferença, entretanto, entre esta célula viva e qualquer célula de qualquer órgão vivo dos animais maiores. As células destes últimos são, para a maioria deles, altamente especializadas; as células do revestimento estomacal desempenham a tarefa especial de produzir ácido e outras substâncias necessárias para a digestão; as células do fígado são especializadas na produção da bílis; as células dos pulmões, na absorção do oxigênio. Um animal unicelular, a ameba, por exemplo, é uma célula que faz todo o necessário para o processo da vida; não há especialização. Ela não tem nariz ou nervo olfativo com o qual cheirar; ela não tem nervos sensoriais com os quais perceber as coisas para evitar o contato com elas. Porém, quando há uma partícula de comida próxima, a ameba a "cheira" ou a "percebe" 
imediatamente e vai atrás dela. Ela não tem pernas para ir atrás da comida, nem mãos para agarrá-la; porém, assim que ela percebe a proximidade de comida, ela imediatamente forma excrescências do seu próprio pequeno corpo, projeções de dedos que são chamados pseudópodes; ela cria um lugar para a comida e, com esses pseudópodes, agarra-a. A ameba não tem boca com a qual engolir a comida; ela forma um pequeno buraco no próprio pseudópode, no ponto de contato com a partícula de comida. O buraco então se torna um pouco maior e, rapidamente, a partícula a ser ingerida fica envolvida como se por lábios; num instante, ela é "engolida" e nós a encontramos dentro da ameba. Naturalmente, a ameba não tem estômago; a parte da célula onde acontece de a comida ser engolida efetua o trabalho do estômago, dos intestinos e do órgão excretor.

Se nós considerarmos a ameba a partir do nosso ponto de vista humano - e nenhum outro ponto de vista nos está disponível - e se nós nos perguntarmos onde está o nariz da ameba, a resposta será: em todo lugar ou em nenhum lugar do seu corpo. Onde estão as pernas, os braços e as mãos da ameba? Em todo lugar, em nenhum lugar nesta célula; a ameba é toda braços e pernas. Onde está sua boca? Toda ela é boca. Toda ela é estômago. A ameba pode desempenhar todo o complexo processo físico-químico sobre o qual a vida está condicionada sem um único órgão especializado. A ameba tem outra característica que chama a atenção. Já que ela não tem órgãos reprodutores e não necessita acasalar a fim de procriar, ela simplesmente se divide ao meio, fazendo duas amebas de si mesma; cada uma dessas descendentes prossegue na condução da vida normal de uma ameba independente. Ela parece não perder substância e, consequentemente, continua a viver eternamente, eternamente no habitual dividir-se ao meio e eternamente funcionando. Ela parece realmente imortal.

Se nós começarmos a examinar o reino animal a partir da ameba para o homem acerca da complexidade da organização, nós deveremos descobrir também que há vários animais vermiculares primitivos que têm uma boca e um orifício anal e nenhum outro órgão. Estes animais podem comer somente através da boca e excretar somente através do orifício anal, porém eles desempenham todas as outras complexas funções sobre uma base "em toda parte" como a ameba, com qualquer parte do corpo. Quando 
gradualmente nos movemos ao longo da escala da complexidade da organização animal, nós logo descobrimos que órgãos definidos são formados para funções definidas, e essas funções já não podem mais ser desempenhadas sobre uma base "em toda parte". Somente os órgãos determinados para as funções particulares podem desempenhar aquelas funções. Se acontecer de as funções serem vitais e os órgãos correspondentes serem destruídos, a função cessa e o organismo morre. Quanto mais complexo o organismo, mais ele depende de uma coordenação adequada de todos os seus departamentos, chamados órgãos, e mais mortal ele é. Ele não sobrevive por si mesmo como a ameba faz; ele deve morrer mais cedo ou mais tarde.

No homem, o germe do plasma parece ser a única parte do organismo que pode reivindicar o mesmo tipo de imortalidade que a ameba; uma parte do germe do plasma parece ser transmitida dos pais para a criança contínua e eternamente. O altamente especializado sistema de organização do homem parece tornar impossível para ele viver para sempre como um indivíduo: o homem paga com a penalidade da morte pela perfeição da sua organização biológica.

Pareceria que nos animais multicelulares, quando uma função da vida é executada por todo o corpo por um período de tempo suficientemente longo, uma parte do corpo torna-se diferenciada e assume determinada função e, a partir de então, ela desempenha somente esta função. Ela desempenha isto automática e eficientemente. Essa parte do corpo desenvolve-se adequadamente e, então, torna-se um órgão especializado. A partir de então, esse órgão é incapaz de fazer qualquer outra coisa, exceto atender a esta sua tarefa própria; ele desaparece, como ele era, "em toda parte" do sistema. Isto sugeriria muito imperativamente que os órgãos estão dirigidos para os resultados das funções da vida. As funções biológicas são básicas; elas não esperam por um órgão ser formado a fim de ser executada. O órgão não é a origem da função da vida; ao contrário, nossos órgãos estão dirigidos para os resultados destas funções. Em outras palavras, a estrutura, ou anatomia, é subsequente à fisiologia. Portanto, atribuir à anatomia, somente aos órgãos, a origem das funções e considerar as funções impossíveis na ausência de órgãos especiais significa negligenciar os princípios do fenômeno da vida. 
Nós podemos afirmar, então, que não há absolutamente razão alguma para acreditarmos que há qualquer organismo, incluindo o homem, que já alcançou a absoluta perfeição de organização, na qual cada função simples está convenientemente determinada para um completamente desenvolvido órgão correspondente. Se esta afirmação de perfeição fosse alguma vez alcançada, nós provavelmente teríamos a nossa frente um ser tão delicado e bem-equilibrado que ele não poderia viver. Até mesmo o menor dano provavelmente o extinguiria da incumbência, já que nenhum órgão, pelo alto grau de especialização, estaria apto a assumir as funções da parte danificada. O delicado equilíbrio poderia ser destruído por uma ninharia.

Do ponto de vista egocêntrico, o homem deveria congratular-se por não ter alcançado essa questionável felicidade da perfeição na organização biológica. A biologia e a medicina já sabem quão perigosa é a extrema especialização orgânica para a vida e para a existência. O cérebro provavelmente é o órgão mais especializado, e qualquer perda de substância cerebral é uma perda insubstituível. As células cerebrais não se regeneram; uma vez danificadas, elas estão perdidas para sempre. Felizmente, até no cérebro há uma latitude biológica. Sabe-se, por exemplo, que certas funções que eram desempenhadas por certas partes do cérebro estão somente temporariamente perdidas após estas partes serem destruídas. Após um espaço de tempo, sem regeneração alguma da substância perdida, as funções são parcial ou completamente recuperadas. Aparentemente, as funções vão e mais cedo ou mais tarde encontram uma parte aproveitável do cérebro para utilizar.

Por mais que as próprias especulações possam sugerir, isto está muito claro: há provavelmente certas funções que o homem é chamado a desempenhar como resultado da sua natureza e que até agora não foram especificadas para qualquer órgão existente no corpo, ou que até agora não foi desenvolvido qualquer órgão anatômico para assumi-las. Teoricamente, nós deveríamos dizer que tais funções, se há alguma, devem trabalhar sobre as mesmas bases daquelas da ameba - sobre bases "em toda parte". Vale a pena nós observarmos, com a maior sinceridade, que uma das maiores dificuldades ao seguir este debate é a sensação de que cada hipótese, não importa qual experiência, de nosso funcionamento parcialmente como 
uma ameba nos parece absurdo, como se algo dentro de nós surgisse como revolta contra esta hipótese. Nós não podemos refutá-la, porém sentimos como alguma reprovação contra a natureza quando a sugestão é feita. Nós até mesmo estamos inclinados a ver nisto pouco mais do que um discurso. Tudo isso é um sinal de certa relutância da nossa parte em levar adiante a linha de raciocínio que foi oferecida, certa resistência psicológica espontânea. Como já foi observado, e como todos nós sabemos, esta resistência deve ser desconsiderada e mantida sob controle quando é apresentado um ponto de vista ou um fato ao qual não estamos acostumados. Caso contrário, nenhum novo ponto de vista ou fato jamais entraria na órbita da nossa mente, e a expansão do conhecimento científico seria impossível.

Qual é o órgão presidindo sobre esta resistência psicológica que nós temos? Ele é um sentimento vagamente percebido. Qual órgão nos faz sentir isso? Onde está a base desse sentimento? Com o que nós sentimos isso? Onde nós sentimos isso? Não há resposta, exceto que nós estamos sentindo isso em toda parte. Quando nós estamos melancólicos, com o que nos sentimos melancólicos? Onde está isso que a base da nossa melancolia repousa? Obviamente, nós estamos melancólicos em toda parte. Podemos estar certos, nós sentimos que os músculos da nossa face estão um pouco contraídos, que nossos olhos se tornam úmidos, que nossos lábios tremem, que nosso peito está um pouco pesado. Toda a massa de nervos, músculos e glândulas estão agindo. Toda nossa estrutura biológica, a maioria dos nossos órgãos, está posicionada em atividade especial. Nossas glândulas lacrimais começam a trabalhar vigorosamente e nós choramos. Outros órgãos estão reduzidos em sua atividade; nosso estômago recua em suas demandas. É hora de comer; nós não comemos nas últimas doze horas; porém nós não temos apetite, nós até mesmo estamos nauseados; isto é, nós rejeitamos toda a comida da qual nosso corpo está necessitando. Tudo isso porque nós estamos profundamente angustiados, angustiados em toda parte. "Em toda parte" não significa sem a participação dos nossos órgãos do corpo. Significa que, como não há um órgão especial para a melancolia, todos os órgãos foram utilizados para essa função particular.

Isso acontece também com a alegria. Nós ficamos alegres em toda parte. Nós ouvimos notícias muito boas e estamos felizes. Os músculos da 
nossa face estremecem com uma exuberância particular; há uma atividade particular em certas glândulas ao redor de nossos olhos, e há uma umidade especial que transmite a eles um brilho característico. Nossa circulação sanguínea está mais ativa. Nosso semblante reluz com alegria. Toda a musculatura do nosso sistema está excitada. Nós gostaríamos de correr em volta ou dançar. Nossas cordas vocais também estão ativas e nós cantamos. Nosso trato digestivo formiga com força - nós desejamos celebrar e devorar um jantar enorme e saboroso. Não há um órgão no nosso corpo que não está ativado. No meio disso tudo, nós podemos ouvir de algum infortúnio que aconteceu a alguém que nós conhecemos; isso é uma pena, mas a alegria impede a entrada da melancolia que somente duas horas atrás nos teria tornado tão compreensivos em toda parte. Agora nós estamos alegres em toda parte - com todo nosso sistema de órgãos biológicos, com nossa anatomia e fisiologia. Não há órgão especial para a alegria; todo o corpo é esse órgão.

O mesmo acontece com outras emoções: medo, amor, ódio, admiração, sentimento de culpa e remorso, sentimento de probidade e indignação, compaixão e desprezo - toda a nuance das emoções humanas, social, antissocial e não social. Até mesmo certas atividades que nos parecem puramente intelectuais, puramente um objeto de julgamento - prazer estético e sentido de aversão, os vários anseios de uma vida melhor, tendência ética, propensão altruísta e egoística -, todas essas são funções em toda parte, nas quais todos os órgãos participam; nós poderíamos chamá-las de funções "totais", como a ingestão de alimento pela ameba. Esse fenômeno total da vida é o que nós chamamos de fenômeno "psicológico"; a este respeito, nós poderíamos considerar as funções puramente fisiológicas da ameba como uma psicológica, porque elas são em toda parte, funções totais.

Assim, após muitas considerações indiretas, nós chegamos a uma definição comparativamente simples do fenômeno psicológico. O fenômeno psicológico é uma função biológica para a qual nenhum órgão especializado é encontrado no organismo vivo. A Psicologia, no sentido verdadeiro do termo, lida com as funções totais do organismo; todos os órgãos especializados em geral, e nenhum em particular, são colocados em ação quando uma reação psicológica ocorre. 
É facilmente visto que essa definição não somente fracassa em excluir a fisiologia e a anatomia, mas as torna o pré-requisito necessário para o funcionamento psicológico; não há psicologia sem um organismo, porém não há órgão de reação psicológica exceto todo o organismo. Essas reações não têm lugar especial; a reação deixa de ser psicológica tão logo uma função especial é assumida por um órgão especial recentemente formado. A partir desse momento, a reação psicológica torna-se apenas puramente automática e fisiológica; seus distúrbios e anomalias tornam-se uma preocupação do médico, do especialista em doenças internas, do cirurgião, do neurologista e do neurocirurgião. Os distúrbios e anomalias das funções totais do ser humano, das funções psicológicas, são preocupações do psiquiatra.

Está claro que o psiquiatra deve conhecer medicina e neurologia, porque as funções totais usam todo o sistema do nosso organismo, e somente um adequado conhecimento desse sistema o habilitará não somente a tornar seu diagnóstico diferencial, mas a compreender mais profundamente a totalidade das reações psicológicas. Além disso, não são somente essas considerações puramente práticas do conhecimento especial que tornam necessário para um psiquiatra ser médico. Há também a necessidade de desenvolver um adequado plano terapêutico que, como já foi salientado, somente um médico possui. O plano terapêutico é de importância particular na Psiquiatria, porque o psiquiatra ocupa-se, na maior parte do tempo, com problemas humanos aos quais o homem, via de regra, é muito intolerante: com malignos desvios neuróticos da vida normal, com perversões, com tendências criminais no homem, com persistente compreensão errônea dos fatos, com incapacidade para trabalhar, sentir e pensar, apesar da ausência de qualquer doença física incapacitadora - todos os quais usualmente despertam no leigo um sentimento de condenação. O psiquiatra deve saber e sentir que é com uma doença que ele está lidando, e não com uma "fraqueza de caráter". Ele condenará isto tanto quanto e tanto menos quanto ele condenaria um homem por estar tendo um ataque de cálculo biliar.

Entretanto um médico com treinamento convencional, que é um pré-requisito e é tudo o que um clínico geral necessita, não é suficiente no caso de um psiquiatra. Reações psicológicas, ao mesmo tempo que põe em 
ação todo o organismo do indivíduo, inclui algo mais, algo que ainda está além do escopo do clínico geral; elas incluem não somente o corpo e sua complexidade, não somente nosso passado psicológico ou biológico, mas também o campo das relações sociais, nosso passado e presente cultural. Quando nós sentimos melancolia ou felicidade, placidez ou fúria, talvez nós usemos nossa circulação sanguínea, pulmões, fígado e cérebro para sentir e manifestar fisicamente nosso estado mental, porém é através da nossa herança social e hábitos que nós expressamos e manifestamos nossos estados mentais. É para aqueles que estão à nossa volta e no mundo que nos rodeia que nós manifestamos nossos estados mentais, nossos impulsos, nossas aspirações, nossa inibição e nosso retraimento. Portanto o psiquiatra, por toda a natureza da sua especialidade, em aditamento ao seu treinamento puramente médico, deve conhecer o homem como um fenômeno cultural e como um elemento social. Este conhecimento não pode ser adquirido via sabedoria revelada, genuína inteligência ou sentido proverbial comum. Ele deve ser adquirido através do estudo sistemático de disciplinas, tais como Psicologia Geral, Literatura, Antropologia, Sociologia e História - que não são ensinadas em escolas médicas e que infelizmente não são ainda oficialmente consideradas pré-requisito para estudos de pós-graduação para aqueles que desejam especializar-se em Psiquiatria. É ao psicanalista a quem o crédito vai para a ênfase nesse treinamento adicional da Psiquiatria. Durante os últimos trinta anos, o desenvolvimento da prática psicanalista clínica efetuou a mais clara realização de que a psicologia do homem não pode ser totalmente abarcada por sua anatomia e fisiologia isoladas, apesar de ela ser limitada por ambos.

Isso nos conduz à questão: o que é um psicanalista? Uma resposta simples é que um psicanalista é um psiquiatra que também usa a técnica psicanalítica no tratamento de doenças mentais. O que é psicanálise e qual é a sua técnica são questões separadas, e elas serão respondidas nestas páginas no tempo oportuno. No momento, é suficiente repetir o que é tão bem conhecido que soa quase como um clichê - a psicanálise estabeleceu, primeiro, a existência do inconsciente (uma afirmação que, como nós atualmente podemos ver, não é completamente exata) e, segundo, que o inconsciente é a origem das doenças mentais. 
O clínico experiente detectará uma doença mental ainda que ele possa ser incapaz de dar qualquer definição compreensiva do que ela é. Ela deve ser produzida na mente, pois é usado o termo "doença mental", em vez de local indefinido. Após séculos ocupando-se com doença mental, a medicina ainda é incapaz de dar uma declaração simples e direta do que ela é. As razões para essa incapacidade são muitas e complexas. Os homens jamais tiveram dificuldade alguma em observar aqueles que são comumente chamados "insanos": eles eram "delirantes"; eles perderam sua cabeça; eles perderam sua razão. A característica enfrentada de um delírio é sua irracionalidade, o desaparecimento da lógica habitual na maneira de uma pessoa pensar. Como foi a primeira coisa observada, ela foi entendida como a verdadeira essência da doença mental. Esta - antes de se tornar flagrantemente um caso óbvio daquilo que o senso comum e o Direito chamam de "demência" - iniciava-se com menos manifestações evidentes, sendo menos suspeitada, bem como não se era suspeito que alguém pudesse sofrer de uma severa doença mental e estar em plena posse do seu poder de raciocinar. Os franceses finalmente reconheceram a existência dessa forma de doença mental, que eles chamaram folie raisonnante - raciocínio insano. Porém o termo "doença mental", introduzido por Linné e Macbride no século XVIII, ainda carregava a sugestão de que era uma doença da mente, da razão, embora termos gradualmente aprendido que esse não era inteiramente o caso.

Tome como exemplo uma severa depressão, na qual a pessoa constantemente sente-se deprimida, desanimada e mesmo suicida. O raciocínio de tal pessoa também é profundamente afetado, na medida em que ele é afetado pela profunda depressão. Tais doenças começaram a ser chamadas "afetivas" - isto é, desordens-emocionais. Esse termo revela a hipótese de que as emoções são algo separado, um departamento especial na personalidade humana, e que essas emoções podem tornar-se anormais e afetar a razão somente parcial e secundariamente. Tudo isso soa muito complicado, e isso é mais propriamente artificial. Para o propósito da conveniência teórica, nós podemos separar a psicologia humana dentro da emoção, da sensação e do raciocínio, porém na prática é totalmente impossível dividir a personalidade humana dentro de tais departamentos. 
Se uma pessoa, por motivos profundos e inconscientes, parar de prestar atenção ao mundo exterior e recolher-se num eterno devaneio, ele falhará - como qualquer pessoa normal que acontece de concentrar-se em algo ou tornar-se distraído - em observar muitas coisas ao seu redor. Ela pode até parar de prestar atenção ao seu redor e ser profundamente perturbada quando impressões externas tentam introduzir-se em sua consciência. O homem que está assim absorto na contemplação de imaginações que ele mesmo gerou, sem auxílio do mundo externo imediatamente circundante a ele, vive a vida do acordado-dormindo. Contingências e exigências da vida diária falham em limitar o curso dos seus pensamentos e ações e ele, a pessoa que faz tão pouco da vida e que exerce tão pouca influência na vida, conduz a vida dos seus próprios ilimitados sentimentos. A este respeito, ele sente-se quase onipotente, pois ele sente-se senhor do seu próprio mundo interior. O alarido, o choro, o chamado vindo do exterior, se registrado de alguma maneira, é imediatamente mal interpretado por ele; sua percepção do mundo externo está perturbada. Exatamente por isso ele caminha na existência cotidiana como um estrangeiro, pois esta parece vazia para ele. Contudo a inexorável necessidade da natureza humana de viver em algum tipo de mundo que está fora de si mesmo o faz criar um mundo imaginário do seu próprio. Ele verdadeiramente ouve vozes que não são ouvidas por ninguém mais - quer dizer, ele sofre de alucinações. Ele está convencido da veracidade de acontecimentos que verdadeiramente jamais ocorreram - quer dizer, ele sofre de desilusões e ilusões. Ele está aflito com a mais refratária das doenças mentais em existência, conhecida agora como esquizofrenia e, no passado, como demência precoce.

Sua razão, naturalmente, parece-nos perdida, mas não está, de fato. Ele somente a aplica unicamente ao seu próprio mundo. Ele a aplica bem, com clareza, conviç̧ão e sequência sistemática. Algo saiu errado. O quê? Foi a habilidade normal do homem para ver as coisas, percebê-las com seus olhos, ouvidos e senti-las? Não, ele parece saber que uma mesa é uma mesa, que uma sinfonia de Beethoven é uma sinfonia de Beethoven e que uma bola de plástico é uma bola de plástico. Porém ele também "sabe" que a mesa tem alguns riscos quase invisíveis, os quais para ele significam misteriosas mensagens de origem misteriosa que somente ele pode compreender. Ele 
também "sabe" que a Heróica de Beethoven, que ele ouviu agora mesmo, foi tocada por "eles" somente a fim de enfatizar com habilidade e convicção únicas que ele morrerá esta noite. Aquele movimento da "Marcha Fúnebre" não soou particularmente bem esta noite? Isto não significa que ele estava sendo prevenido da sua morte intempestiva? O comentarista não falou para a audiência que originalmente Beethoven dedicou a sinfonia para Napoleão, porém depois riscou o nome dele? O comentarista foi surpreendentemente enfático sobre isso porque ele "estava falando" para tornar claro para ele - o esquizofrênico, um dos milhares de ouvintes - que não foi a Napoleão, mas a ele que a execução da sinfonia foi dedicada.

Você encontrar-se-ia argumentando em vão se disser que a execução não foi excepcional, que na verdade ela foi muito medíocre, que os instrumentos de sopro soaram enfadonhos e sem inspiração e que uma das trompas até soou uma nota áspera em uma ou duas ocasiões. O esquizofrênico imediatamente concordará. Naturalmente, tudo isso é verdadeiro, porém há uma boa razão para isso. Foi a mera falta de distinção que emprestou ênfase à execução; foi aquela nota áspera que tornou claro que havia escárnio em toda a execução. Foi o comentarista que organizou tudo isso. Ao enfatizar que o nome de Napoleão foi riscado, ele pretendia dizer que ele, o esquizofrênico, não era um Napoleão, mas um pequeno e inexpressivo homem. O comentarista então organizou as coisas de tal modo que ninguém poderia enganar-se sobre o fato de que tudo foi feito para aborrecer e humilhar o homem. Eles executaram a "Marcha Fúnebre" como se ela fosse um suspiro diabólico, e eles colocaram a dupla nota áspera a fim de tornar isso mais insultante, sarcástico e ofensivo. Por favor, observe que todo o aborrecimento estava concentrado nos instrumentos de sopro - esse não foi um acidente, nenhuma falha do fagotista, mas uma insinuação particular para o fato de que ele, o esquizofrênico, muitos anos atrás, quando garoto, divertia-se tentando tocar cantigas simples num pífaro feito de bambu. "Eles" estavam tentando dizer a ele que ele ia morrer como um tolo e que ele não era Beethoven, que ele jamais seria. Como "eles" estavam tentando dizer-Ihe que ele não era Beethoven? Esta era a Terceira Sinfonia, e sua Primeira Sinfonia soou como Mozart, e a última criação musical de Mozart foi o grande Réquiem; Mozart faleceu antes 
de terminar o Réquiem; ele tinha trinta e cinco anos e então ele tem, o esquizofrênico, trinta e cinco anos.

Naturalmente, tudo isso é irracional, porém a pessoa em questão parece profundamente convencida e apta a organizar todos os fatos para se ajustarem a sua convicção, apta a criar um número de fatos novos que estão nitidamente em condições de serem convincentes. Evidentemente há algo, uma força poderosa, um tipo de sempre presente e sempre poderosa necessidade de interpretar tudo à luz da sua própria convicção. Essa necessidade não é obviamente de origem intelectual ou racional, tampouco de origem sensorial, porque suas impressões sensoriais parecem intactas - ele não percebeu a nota áspera, ele não reconheceu a sinfonia? A dificuldade parece ser mais profunda. Nós podemos não estar aptos a definir isso imediatamente; nós podemos não compreender sua natureza, porém nós podemos ver que essa dificuldade está dotada com uma energia poderosa para defender a razão do homem, sua apreciação dos fatos, seu relacionamento com o mundo exterior, em constante servidão e subjugação. Há a necessidade de acreditar que o mundo está preocupado somente com seu próprio pressentimento de morte, que todos e tudo estão colocados em movimento a fim de falar-Ihe sobre sua própria morte. A história, a cultura, a política, a arte, a filosofia, o comércio e a indústria são de modo idêntico desprezados porque as preocupações da pessoa são mais importantes do que todas as outras funções do universo ou, então, são trazidos à órbita das suas próprias demandas irracionais. O enfermo será o último a admitir que ele seja megalomaníaco a esta extensão. Sua conduta pode mostrar exatamente o contrário: ele pode parecer suave, gentil nos modos, humilde e simples; pode haver um calmo e misterioso sorriso combinado com um inconfundivel encolher dos ombros. Novamente, sua deturpada megalomania é demasiadamente visível para admitir qualquer dúvida.

Tudo isso - a necessidade megalomaníaca, o desordenado empenho para reajustar e interpretar erroneamente toda ocorrência no mundo externo à luz dessa necessidade - aí está sem o homem estar realmente consciente disso. Isso está tão separado dele que ele considera tudo muito natural e inevitável. A necessidade é inconsciente, porém é potente e dinâmica ao ponto de ser capaz de perverter todo o sentido de realidade. 
Ela cria uma nova e puramente pessoal realidade, independentemente de qualquer fato exterior.

Onde está a base desta força inconsciente? Ela parece afetar não somente as próprias funções do cérebro do homem, mas também seu apetite, seu humor, suas funções corporais em geral, sua perspectiva social e sua tendência cultural. Ele é místico. Ele é supersticioso e também sutilmente apto a perceber tudo o que realmente ocorre. Sua necessidade anormal parece estar "em toda parte". Essa é uma necessidade psicológica, uma necessidade "total".

Os antigos escritores viam nisso "raciocínio demente" e, se a ideia central estava bem definida e aparentemente fracassava ao interferir com certas atividades normais do indivíduo, isso era chamado de "insanidade parcial", como se o homem realmente estivesse dividido em partes e ainda permanecesse inteiro. Não há partes autônomas na personalidade humana. A dor da pele solta sobre a cutícula desenha o humor e a atividade de alguém, não importa quão bem o indivíduo "se controle". O verdadeiro fato do autocontrole significa um esforço total da constante vigilância total. Notícia triste afeta toda pessoa desatenta ao autocontrole. Reações psicológicas são totais e a personalidade do ser humano é uma totalidade. Essas reações emergem no ser humano de necessidades variadas, que nem sempre são conscientes e na maioria das vezes são totalmente inconscientes. Elas emergem de sentimentos e emoções preferivelmente vagos e indiferenciados. É a compreensão desses sentimentos, emoções, impulsos, ímpetos, instintos, se você deseja, que conduzem para a compreensão da psicologia humana, normal e anormal, capacitando o ser humano a libertar seu raciocínio da prisão que na verdade não é somente da pessoa esquizofrênica ou deprimida, mas de todos os seres humanos, em diferentes graus.

O leitor está convidado a não aceitar esta afirmação dogmática de fé. Deverá ser elaborada e devidamente provada, porém, a fim de fazer isso, nós devemos aprender mais sobre os detalhes do inconsciente - da sua estrutura, das forças disponíveis para isso e da maneira pela qual ele age. Esse trabalho científico, que é tanto difícil quanto complexo, foi feito nos últimos quarenta ou cinquenta anos por Freud e seus discípulos. 


\section{REFERÊNCIAS}

BENYUS, J. M. Biomimicry: innovation inspired by nature (repr). New York, N.Y: Harper Perennial, 2008.

CAPRA, F. O tao da física um paralelo entre a física moderna e o misticismo oriental. Tradução de M. Schenberg, J. F. Dias e N. R. Eichemberg. São Paulo: Cultrix. 2005.

CAPRA, F. O ponto de mutação: a ciência, a sociedade e a cultura emergente. Tradução de A. Cabral. São Paulo: Editora Pensamento-Cultrix LTDA, 2006.

CAPRA, F. A teia da vida: uma nova compreensão científica dos sistemas vivos. Tradução de K. Amana. São Paulo: Cultrix, 2010.

ZILBOORG, G. Mind, medicine, and man. Oxford, England: Harcourt, Brace. 1943 
